\title{
'Mulheres Fortes e com Estilo': Protagonismo musical e territorialidades femininas no movimento underground cristão
}

\author{
'Strong Women and with Style': Musical leadership and territorial female to \\ Christian underground movement
}

\author{
Diogo da Silva Cardoso \\ Universidade Federal do Rio de Janeiro \\ diogo_georeg@yahoo.com.br
}

\section{Resumo}

Este texto tem como objetivo apresentar a cena underground cristã a partir da afirmação identitária e do protagonismo das jovens mulheres do 'metal cristão'. A proposta é pensar as espacialidades dessas jovens que, vistas enquanto 'mulheres de Deus', estão inseridas no quadro heteronormativo próprio das culturas cristãs (mesmo nas vertentes mais pós-modernistas e alternativas) e, com isso elas negociam, se ajustam e, por fim, criam suas próprias culturas de espaço e territorialidades de acordo com as necessidades da comunidade religiosa e com a carência de 'mão de obra' feminina para levar o cristianismo às culturas e redes juvenis alternativas que tem no seu público feminino um contingente historicamente invisibilizado, subordinado aos códigos de conduta dos sujeitos masculinos e negligenciado pelas práticas missionais das igrejas hegemônicas.

Palavras - chaves: Underground cristão; jovens emergentes; territorialidade feminina; subgêneros de heavy metal; campo religioso cristão.

\begin{abstract}
This text aims to present the Christian underground scene from the affirmation and the protagonism of the young women of 'Christian metal'. Its proposal is to think the spatialities of those youngsters, seen as 'women of God', who are included as part of their own heteronormative Christian cultures (even in the most postmodernists and alternatives currents), and consequently they deal with, fit, and, finally, create their own cultures and territorial space according to the needs of the religious community and the lack of a female 'manpower' to bear Christianity to alternative youth cultures and networks that have on their female audiences a contingent that are historically made invisible, subjected to behavior codes of the male subjects and neglected by the missional practices of the hegemonic churches.
\end{abstract}

Keywords: Christian underground; emergent youths; female territoriality; subgenres of heavy metal; Christian religious field. 


\section{Introdução}

Já se tornou senso comum afirmar que o campo religioso brasileiro tem passado por constantes e duradouras transformações e mais, que a tendência é que o sincretismo e o fundamentalismo andem de mãos dadas na configuração de novos movimentos religiosos e na reprodução das religiões tradicionais hegemônicas. De certo que tudo isso é verdade, mas quem se fica presa nessa constatação e não mostra, de fato, o que realmente está mudando e permanecendo no campo fica preso num formalismo lógico que é característico do pensamento pós-moderno (EAGLETON, 2003), incapaz de mensurar as estruturas que conformam os sentidos e ingênuo (para não dizer fraco!) quando o assunto converge para as inter-relações entre culturas, instituições e grupos sociais.

Neste artigo, o contexto analisado é deveras múltiplo, ambivalente e nuançado nos mínimos detalhes. E quando as relações de gênero também são postas em questão, as coisas ficam ainda mais difíceis de analisar e colocar num frágil quadro explicativo. $\mathrm{O}$ movimento estudado será o underground cristão e a comunidade Metanoia é o lugar privilegiado para compreender um pouco como as jovens adolescentes e adultas tem construído sua condição feminina dentro de um cenário duplamente marcado por: 1) duas cosmovisões fortemente masculinizadas (cristianismo protestante e cena musical heavy metal); e 2) pelas possibilidades múltiplas de afirmação do sujeito feminino através da contestação da opressão insidiosa e silenciosa pela qual passa a mulher, e da afirmação como agentes ativos na construção de grupos, instituições e relacionamentos. No underground cristão não é diferente, dado que muitas dessas jovens mulheres assumiram a liderança de igrejas, organizam eventos, são consideradas suporte espiritual indispensável para a realização do trabalho duro dos homens e, por fim, dão um toque feminino e sensível a um contexto em que a masculinidade torna-se mais afrouxada e os homens necessitam de outros meios instrumentais e simbólicos para adquirir status e privilégios.

No decorrer da primeira década deste presente século, o movimento fortificou-se e magnetizou segmentos estéticos mais politizados (hip hop) e visualmente mais convencionais (surfista, emo, 'hippie de boutique') e não são mais tão repudiados pelos evangélicos, mas a territorialidade diferencial nas grandes e médias cidades continua a fazer desses grupos um caso peculiar de contestação e de transformação dos valores e das práticas convencionais, ajustando-as para as espacialidades juvenis líquidas, fragmentadas e deslocadas encapsuladas no igualmente fluido tecido urbanometropolitano contemporâneo. As territorialidades dos jovens undergrounds tem um veio extremamente simbólico, ao qual veem a cidade como um campo de batalha não só material, mas espiritual, e isso os faz planejar as ações cotidianas nos episódios de evangelismo, apresentação artística e contatos com seus pares. Numa perspectiva construtivista, pode-se dizer que os agenciamentos coletivos revelam muito mais que a percepção e vivência do sagrado dos asseclas do underground cristão. Revela um mundo de experiências religiosas que, ao se conectar com as novas tecnologias da informação e da comunicação, coloca os jovens adolescentes e adultos diante de um enorme paradoxo: aderir à religião dentro da igualmente religiosa cultura moderna e pós-moderna da vida secularizada (EAGLETON, 2003, p. 123), ou fechar-se em dogmas, doutrinas e comunitarismos 'autossuficientes', tendência vista em algumas ramificações do protestantismo histórico e do pentecostalismo.

Para exemplificar, trago na última parte os resultados da investigação realizada na comunidade religiosa Metanoia, localizada no Conjunto da Maré, em Bonsucesso, Rio de Janeiro. É tida por boa parte dos undergrounds como 'a Igreja mais underground do Brasil', 'o grupo mais forte e coeso da cena', a que 'tem o pastor mais radical do metal', e isso por si só é um atrativo para que se investigue o papel das jovens mulheres do Metanoia nessa fama toda, afinal, não é só o pastor ou os músicos das bandas que construíram a reputação e longevidade da comunidade. Tanto no território religioso como nos trajetos vivenciados na cidade do Rio de Janeiro e seu entorno (Duque de Caxias, Mesquita, Nova Iguaçu, Japeri, Seropédica), as mulheres do Metanoia tem comportamentos próprios para cada situação, tecem relações mais afetivas e duradouras com pessoas do mesmo gênero e, por terem uma postura ativa e visualmente chamativa (um visual gótico ao mesmo tempo sombrio e sensual), dão um ar mais 'moderno' e feminino a um contexto que mescla duas culturas falocêntricas, o cristianismo e o mundo artístico do heavy metal, ou seja, elas têm de negociar, se atritar em alguns casos, mas quando o assunto é espaço, suas territorializações sempre se dão na ambivalência dessas duas cosmologias, tanto no comportamento apresentado nos espaços públicos quanto nas restrições impostas nos espaços privados em shows seculares com bandas famosas, há determinadas áreas (os camarins das bandas, por exemplo) onde o acesso feminino fica restrito às que exercem alguma atividade na organização do evento e, é claro, as 'mulheres de programa', estas últimas, com

Diogo da Silva Cardoso 


\section{privilégios bem definidos.}

Para conseguir adentrar nesse complexo universo, usei como metodologia a observação participante junto a uma etnogeografia multilocal (CLAVAL, 1999; MARCUS, 1995), que permite desenvolver interpretações interessantes a respeito dos inúmeros processos que podem acontecer em múltiplos territórios ou num território reconhecido por sua pluralidade de culturas e agentes políticos (HAESABERT, 2007). Sem clamar por um pluralismo formal e ingênuo, a tentativa de entender os processos de uma rede de sociabilidade religiosa dentro de múltiplos contextos situacionais permite resolver o dilema geográfico do underground cristão, que é conseguir uma geograficidade que dê visibilidade e reconhecimento ao movimento. Tal projeto, diga-se de passagem, está ainda nas pendências iniciais e tem como expectativa tanto promover o diálogo e a cooperação com as denominações evangélicas tradicionais (o diálogo com os católicos é um tabu entre eles), como também pode trilhar o caminho do fechamento, do sectarismo, do essencialismo identitário que pressiona os prosélitos a ver a sua comunidade como a única saída desse mundo secularizado, apocalíptico e também como a única alternativa materializada em um contexto cristão nitidamente pós-cristão (KIMBALL, 2008), onde, no dizer deles, o utilitarismo (ética salvacionista) e a influência de pastores-empresários contaminou os valores do 'Cristianismo Primitivo', grande arquétipo revisitado sempre que há divergências de visões no cristianismo ocidental.

O Metanoia, comunidade religiosa privilegiada neste estudo, não responde a todas as questões sobre o papel do gênero nas novas religiosidades, mas coloca um ponto central sobre como essas mulheres que pertencem a uma rede de sociabilidade alternativa (gótico, dark e heavy metal) configuram territorialidades diferenciais dentro de distintas esferas da vida (religião-trabalho-estilo de vida), principalmente nos momentos religiosos, quando elas travestem-se de cristãs subversivas, dotadas de um estilo radical que espelha o tipo de Deus e de Igreja que acreditam - um Deus sério e não-preconceituoso e uma Igreja aberta a 'todos'.

\section{Mulheres Fortes e com Estillo: A territorialidade feminina das 'metanoianas'}

O Metanoia é uma comunidade religiosa localizada no bairro Nova Holanda, dentro do Complexo de favelas da Maré, adjacente ao bairro Bonsucesso. O
Metanoia tem sua 'fama' associada a dois fatores: primeiro, a liderança inconteste de Enok Galvão, considerado um dos gurus do heavy metal carioca, não a toa, sempre é requisitado para as palestras que tem como tema o heavy metal secular e cristão, e é figura cativa nos shows undergrounds, pois a sua presença é sempre solicitada pelos organizadores dos eventos (assim como um presidente de um país é requisitado para entregar uma obra pública de grande porte); e, segundo, o espaço estético e religioso do grupo é uma soma de elementos do heavy metal e de símbolos ressacralizados ou 'asfixiados' por estarem em um território religioso ${ }^{1}$, colocando-o, aos olhos dos membros e simpatizantes, como uma autêntica 'obra de arte'.

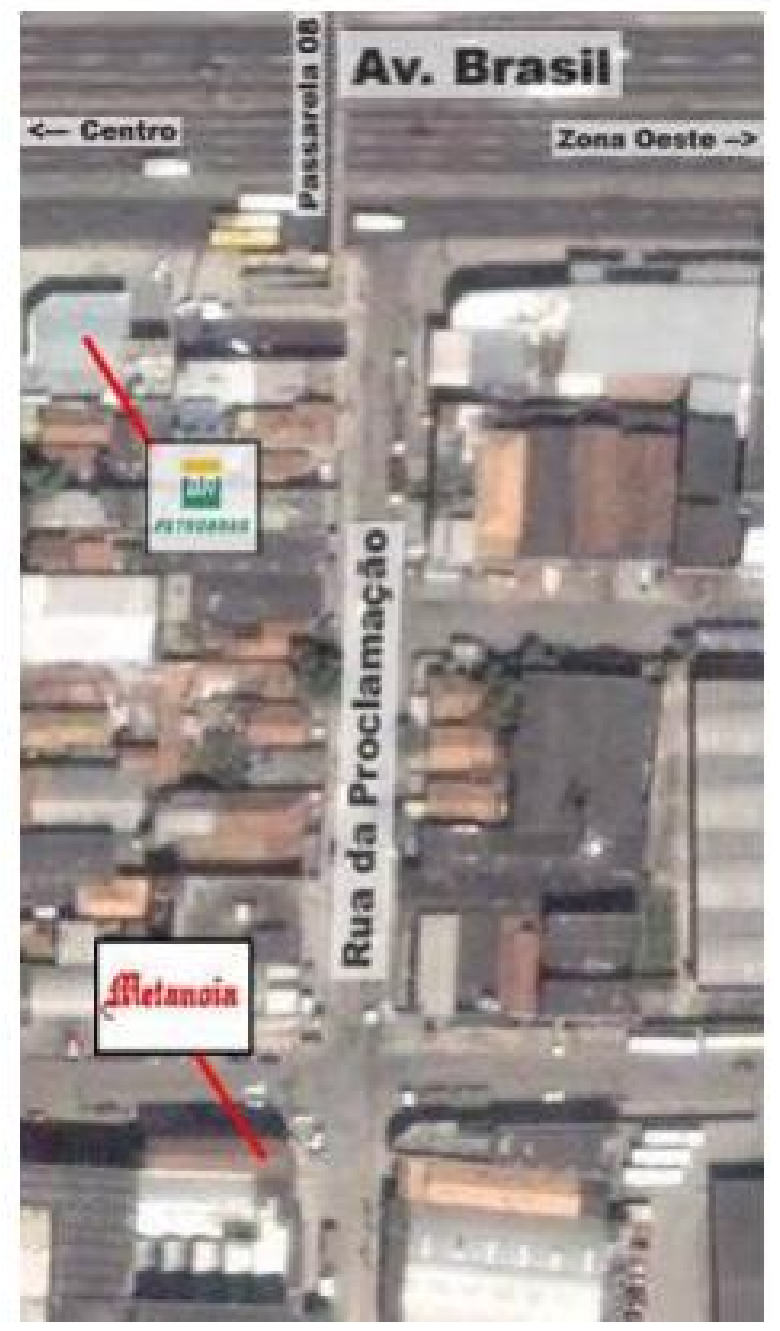

Imagem 1: mapa de localização da comunidade nas imediações da Avenida Brasil.

Fonte: $<$ http://www.metanoiaunderground.com.br/inde x.php?option $=$ com_content $\&$ task $=$ view\&id=12\&Itemi d=28> Data de acesso: 05 jul. 2008.

Diogo da Silva Cardoso 
A ideia de transformar o espaço do Metanoia num 'santuário de metal cristão' pode ser traduzida, em termos geográficos, na produção de um espaço estético que visa magnetizar todo cristão ou metaleiro que consiga compreender e desfrutar dos códigos desse espaço sagrado. Por códigos, refiro-me às gírias do pastor, aos riffs distorcidos de guitarra, aos vocais guturais do Joab cabeludo ou do Alex, às rodas de fogo em meio à adoração a Deus, aos abraços suados depois da 'transcendência', às falas agitadas após o culto etc., que são os elementos peculiaridades do Metanoia.

A estetização do lugar busca conciliar elementos seculares (por exemplo, os discos de vinil escancaradamente não-cristãos afixados na parede) com artefatos que remetem à crença alternativa do grupo, como o caixão com versículo bíblico, a faca fincada em uma suposta cabeça de bode, as alegorias e desenhos que enfeitam o salão de culto. $\mathrm{O}$ reforço das referências simbólicas extremas (CANEVACCI, 2005) - agora ressacralizados à luz das Escrituras -, e uma compulsão por evangelizar headbangers, góticos, vampiristas e outras culturas transgressoras é o diferencial do Metanoia, o que confere a eles certo status e prestígio cultural e religioso dentro de determinados circuitos (igrejas renovadas nos municípios de Nova Iguaçu e Seropédica) e relacionamentos (grupos de amizade na Passarela do Rock, em Mesquita ou no evento Ajuntamento das Tribos).

Não há uma preocupação primordial no universo underground cristão em manter os laços afetivos (como os evangélicos) ou aumentar a conquista material (como os neopentecostais): suas preocupações se centram na missão que precisam cumprir. A meta é ser o canal entre Deus e a 'escória da sociedade' - um jargão usual entre eles - sem se comprometer com vínculos associativos formais ou outros 'problemas de crente'.

A cidade é compreendida pela cosmologia do underground cristão como a paisagem onde o Mal está instalado. A cidade é apenas a morfologia material que esconde, no plano transcendental, a existência de hordas malignas que ameaçam, desde os tempos bíblicos, os planos de Deus na Terra. A cidade impõe uma dificuldade extra pela sua concentração de pessoas e culturas distintas, abrindo caminho para um 'campo de batalha material e espiritual' cujo objetivo é vencer as dificuldades da distância estrutural e as 'ciladas do Inimigo'2.

É do pastor Batista (Crash Church) a frase mais enérgica sobre o modo catastrófico como o underground vê a cidade: "Deus revela os planos do Diabo, e cabe a nós intervir. O Crash é um exército que deve conquistar a cidade através da interceptação das ciladas do Inimigo" (2010, comunicação pessoal). Com essa frase, não há dúvida da guerra simbólica instaurada entre o 'nós' e o 'mundo lá fora'.

Nas palavras de Enok, um guru em assuntos de missões urbanas ${ }^{3}$, tem o seguinte lema que repercute no discurso de toda a membresia metanoiana: "Quem quiser estar conosco, vai ter que dar duro, suar sangue, batalhar contra o Inferno; quem for fraco, é melhor ir para outro lugar, ficar sentado no banco de uma igreja de 'crente"'. Enok é procurado sempre pelas igrejas evangélicas e alternativas para falar da sua experiência missionária e dar dicas de onde andar e com quem andar nos becos e submundos da cidade.

Incorporar o habitus metanoiano é, sem medo de mistificar, acionar uma 'identidade de luta' na qual os nativos são portadores de uma 'missão', na verdade uma tarefa, que é denunciar os vacilos das denominações evangélicas e, ao mesmo tempo, combater o Mal incrustado nas zonas perigosas da cidade com "jejum, oração e combate direto junto aos perdidos” (Enok, 2008, comunicação pessoal).

Essa cosmologia atuante é tributária do constructo imagético-discursivo do pentecostalismo, do qual o maior representante é pregação que encara a cidade como uma topografia material que oculta à manifestação das 'hordas de Satanás' no plano espiritual é, sem dúvida, tributária do constructo imagético e discursivo elaborado pelos pentecostais, do qual o maior representante é a Assembleia de Deus com seus incontáveis pontos de pregação em cada bairro das periferias das cidades brasileiras (pelo menos é assim no Rio de Janeiro).

Quem não tem pulso suficiente para enfrentar esses desafios impostos pelo universo alternativo, que impele a um modo de agir que assusta tanto os cristãos materialistas quanto os idealistas nostálgicos, provavelmente abandona o movimento, atitude muito frequente mesmo em comunidades aparentemente consolidadas.

Permanecer nessas comunidades é um desafio de mão dupla: primeiro, porque é necessário estar ambientado com os estilos que essencializa o grupo: punk, hip hop, metal, emo, ou outro qualquer; Depois, o fiel é iniciado nos rituais, nos códigos de convivência, nos simbolismos, nas atividades culturais, em suma, no habitus do grupo, de modo que ele incorporará e vivenciará os aspectos domésticos do grupo, o âmago da coesão grupal.

O cristão underground, sempre que tem um naipe de escolhas de igreja, opta por aquela comunidade que apresenta uma 'singularidade', descrita em termos de musicalidade, relacionamento, diversão, leveza nas hierarquias e, sobretudo, conforto espiritual. Conforme a entrevista do jornalista Gabriel Louback $^{4} \mathrm{em}$

Diogo da Silva Cardoso 
algumas comunidades de São Paulo, estou cada vez mais inclinado a acreditar que a ideia de 'abrigo' é a metonímia geográfica que explica a busca tão obstinada das juventudes religiosas por um lugar que os conforte espiritual e esteticamente.

Em termos nativos, eles se autodenominam 'remanescentes', ou seja, nutrem a ideia de que são o trigo que restou do imenso 'saco de joio' que é o cristianismo em suas múltiplas vertentes institucionalizadas 5 . Se autorreconhecem como a 'boa safra', cuidadosamente semeada e colhida por Deus (como disse um metanoiano, foram escolhidos a 'dedo') para alimentar as novas gerações com alegria e dignidade. Com essa concepção, buscam legitimidade para evangelizar os jovens marginais e subversivos da sociedade.

Eles veem a cidade, e especialmente os 'espaços de perdição', como um campo de batalha 'espiritual'. Os territórios profanos precisam da 'Luz do Senhor', e para que isso ocorra, cabe a eles 'sitiá-los' por meio dos três pilares fundamentais do evangelismo: jejum, oração e encontro face a face. Os dois primeiros podem ser feitos à 'distância', por meio de reuniões no templo, orações nos lares, clamores nos chats e fóruns da web etc.; mas o último pilar, esse sim é, sem dúvida, o mais importante de todos: o momento em que o 'escolhido', munido da 'Palavra e da Unção de Deus', será o canal para que o Outro aceite a Jesus Cristo e assuma esse compromisso em alguma igreja - de preferência uma igreja underground ou com perfil anti-institucional!

$\mathrm{Na}$ próxima página, o mapa nos dá uma visualização didática e provisória da multiterritorialidade do Metanoia no Estado do Rio de Janeiro, onde a espacialidade do grupo não se restringe ao seu território religioso: o grupo construiu uma densa e articulada uma rede de relacionamentos, produção de shows e ações religiosas com vários grupos e líderes que apresentam uma agenda de prioridades semelhante a deles - evangelização de jovens de culturas alternativas.

E é nesse circuito espacial construído e experienciado por cada integrante do Metanoia que as mulheres vão ter a oportunidade de mostrar suas potencialidades, seja como líderes, sacerdotisas, levitas $^{6}$ (termo evangélico para o músico devidamente consagrado pela Igreja para tocar no ministério de louvor). Em um cenário juvenil marcado por termos pejorativos ao gênero feminino, tais como 'mariagasolina', 'maria-xampu'7 e, num termo mais recente, as 'maria-palquinho', as mulheres do Metanoia criam uma lógica diferente a ser seguida não só no interior do espaço de culto, mas em toda a vida cotidiana. Termos toscos como esses são repelidos veementemente pelas jovens cristãs que lidam com as culturas alternativas, visto que o reconhecimento e respeito são caracteres a serem levados em consideração tanto por cristãos homens e mulheres no momento de interagir com os outros seculares.

A diferença de gênero é um impasse no grupo, aliás, constitui-se num tabu em todo o contexto emergente cristão. Em algumas ocasiões, presenciei os já clássicos "aqui o assunto é só de homem, não de mulher”, ou "a reunião será só para as mulheres do Metanoia, nada de homens, hein!"8. Porém, mesmo com os critérios de demarcação territorial das reuniões 'dos homens' e 'das mulheres', as mulheres têm presença marcante nas atividades do grupo: no mínimo, uma mulher está hoje na linha de frente dos eventos ou de qualquer outro afazer que requeira a 'sensibilidade' ideologicamente atribuída a elas (oração, cuidar das crianças, 'ficar na cantina', recepcionar as visitantes mulheres).

Elas, notadamente as mais jovens, não se rebaixam à condição de simples 'mulheres submissas a seus namorados e maridos headbangers': elas varrem o chão e ficam na cantina da igreja, mas também promovem eventos 'feminizados', montam bandas, frequentam os circuitos de lazer noturno, e nunca se viu algum 'macho' do Metanoia impor alguma coisa para sua namorada/mulher - pelo menos na gente do grupo...

Uma prova da vitalidade das mulheres metanoianas está no Metanoia Gothic Fest, hoje o único festival regular realizado no Espaço Metanoia Com um número de participantes razoável para a cena independente, elas invertem consideravelmente a condição frágil e passiva da mulher cristã (ainda mais quando se é jovem!).

A identidade feminina é um bem precioso, mobilizado para conquistar 'prestígio' e status na cena musical. As jovens do Metanoia foram inteligentes e ativas o suficiente para criar um nicho próprio de sociabilidade e de atuação missionária. Em conversas informais, deixaram claro que Deus tem chamados para todos, e as mulheres não escapam disso. Para essas jovens, Deus não trabalha hoje do mesmo modo que fora registrado nas sociedades bíblicas. Nesse período, o homem era a representação primeira e preferida de Deus na Terra, restando às mulheres o papel de se submeter as várias hierarquias construídas pelo homem: rei, pai, marido, pastor, patrão, guerreiro, comerciante, burocrata, entre outros.

Como define uma delas: "pensar dessa forma hoje é ser um machista idiota, que não entende nada do novo mundo que vivemos. Como pode os 'crentes' [homens] acharem que as mulheres devam se submeter a eles da mesma forma que está escrito na Bíblia. Isso é uma leitura torta, descontextualizada!".

Diogo da Silva Cardoso 
'Mulheres Fortes e com Estilo': Protagonismo

musical e territorialidades femininas no movimento

underground Cristão

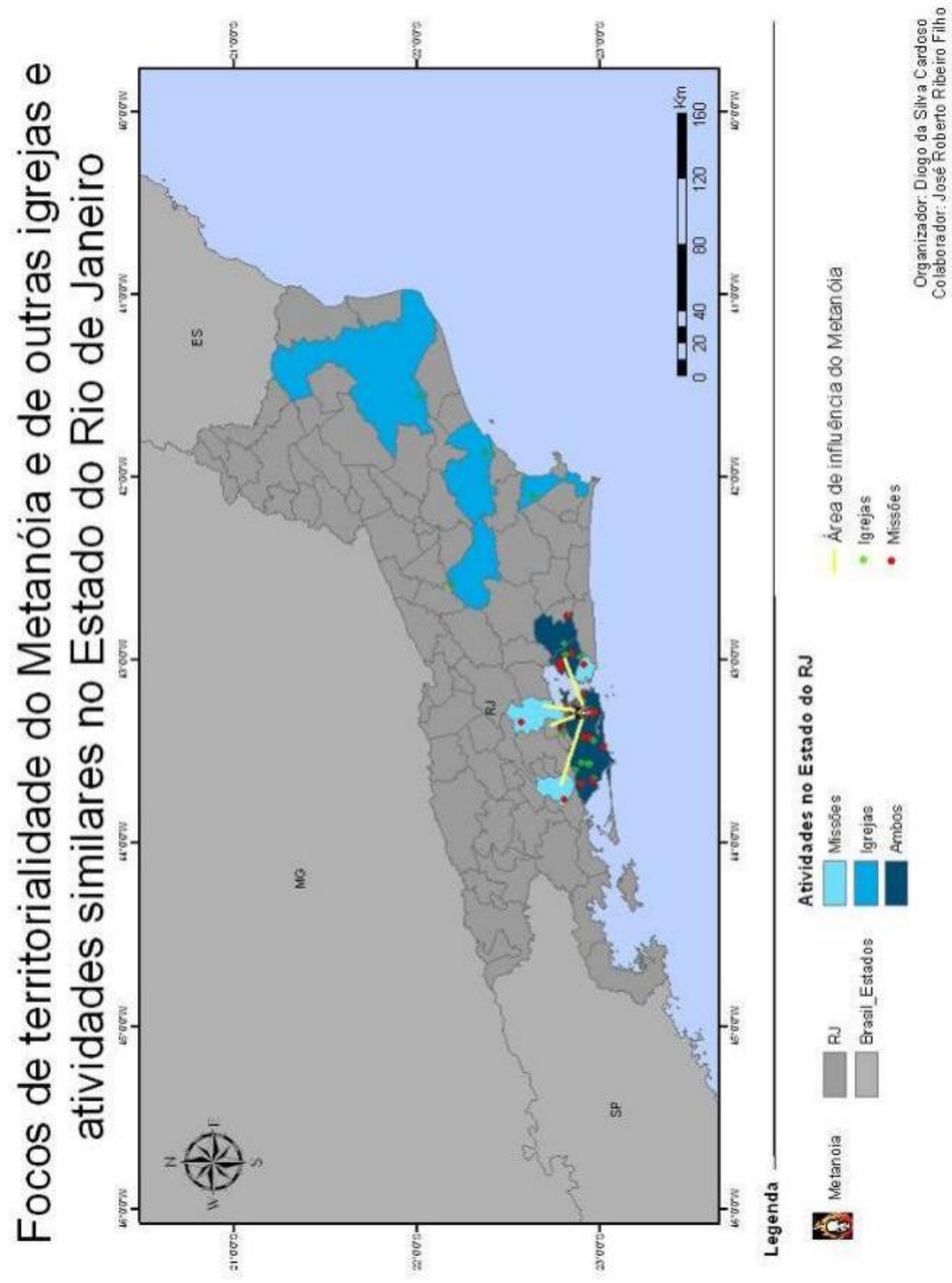

Diogo da Silva Cardoso 
'Mulheres Fortes e com Estilo': Protagonismo

musical e territorialidades femininas no movimento

underground Cristão

Foto 8: o espaço novo e ampliado do

Metanoia inaugurado no Enok Festival 2009.

Fonte: arquivo

pessoal.

Para além do cotidiano feminino, as jovens do Metanoia operam uma 'subversão consentida' dentro dos eventos e discussões de grupo. 'Consentida' porque, no geral, é preciso o apoio do Enok e das mulheres "espiritualmente maismadur as' (Denise, Alessandra, Andréia). Amor, paixão e honra são os elementos trazidos à baila por elas para dar um 'toque feminino' às programações rotineiras e extra-locais.

Uma produção de espaço para ritualização dos subgêneros gothic, doom e symphonic metal que choca e subverte temporariamente a lógica machista introjetada na 'cena' metal. A força e a apropriação plena do território passam para o lado das mulheres, e o adornamento do espaço espelhará a mudança ocasional. Forma-se uma simbólica 'subcultura' de resistência feminina (WELLER, 2005) dentro de uma irmandade religiosa. E nesse diapasão que Silva (2005) comenta:
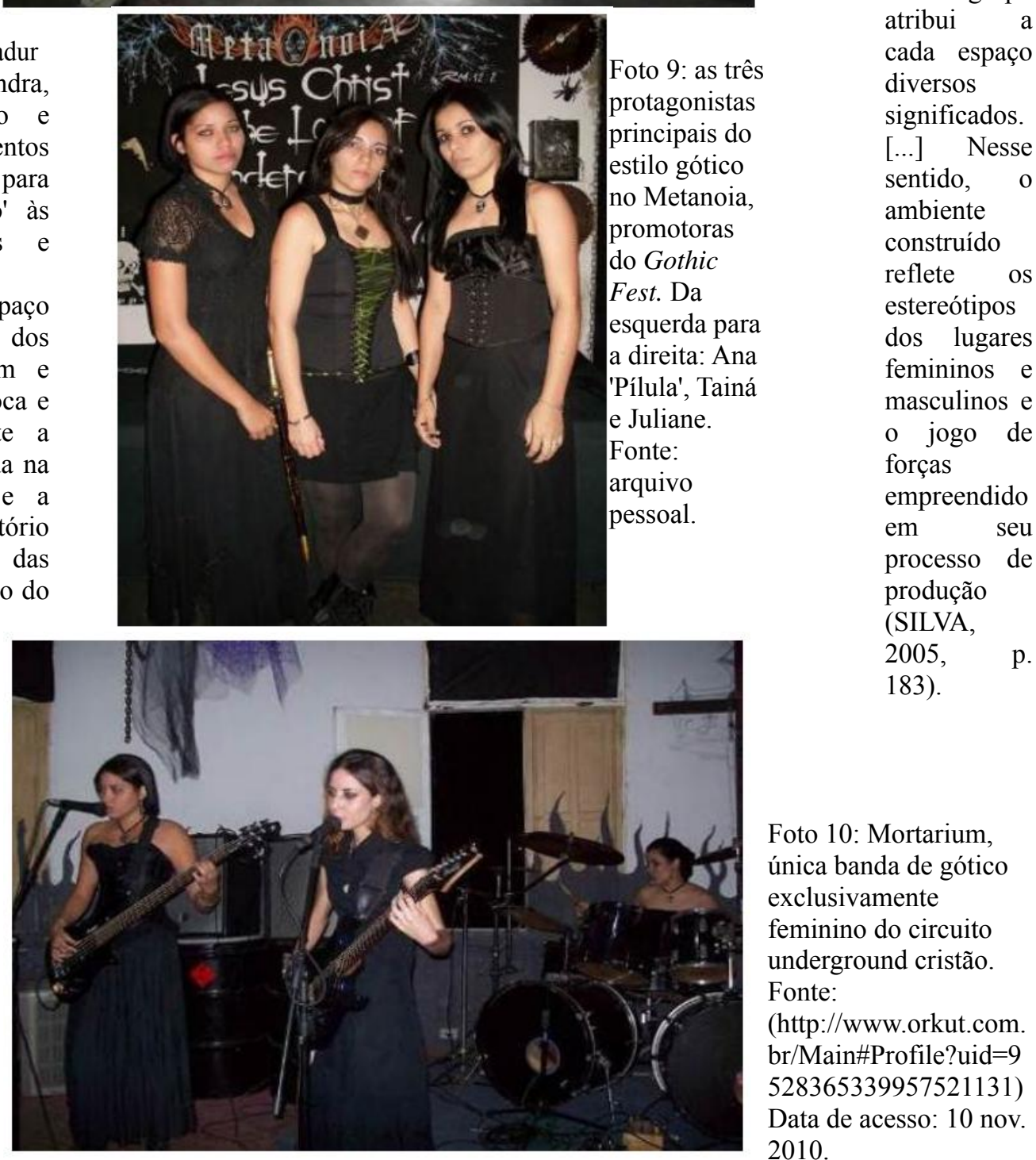

feminino é construído

nas

estruturas de dominação socioespaciai s. As tensões fazem parte das práticas diárias na relação entre grupos sociais e espaço, pois cada grupo atribui a cada espaço diversos significados. [...] Nesse sentido, reflete os estereótipos dos lugares femininos e masculinos $\mathrm{e}$ jogo de forças empreendido em seu sso de 2005 183).

Foto 10: Mortarium, única banda de gótico exclusivamente feminino do circuito underground cristão. Fonte: (http://www.orkut.com br/Main\#Profile?uid=9 528365339957521131) Data de acesso: 10 nov 2010.

Diogo da Silva Cardoso 
Um dilema vivido pelas mulheres do Metanoia e do underground cristão e emergente em geral reside em não cair em um dos dois extremos: ser totalmente 'submissa' ou despudoradamente 'rebelde', principalmente quando o assunto é relação conjugal. É um dualismo que tem suas origens na crença bíblica de que a mulher tem a obrigação de colocar em primeiro lugar o 'Ego' do marido, conforme a carta paulina aos Colossenses (cap. 3, ver. 18) que diz: "Esposas, sede submissas ao próprio marido, como convém no Senhor". Esse capítulo emblemático apresenta (na versão atualizada) o imodesto título 'Responsabilidade Social'. Mas como na era (pós)moderna as interpretações são multivariadas, quase infinitas (VATTIMO, 2006), a de se colocar esses escritos em discussão nos respectivos contextos sociais onde pretende ser o guia literário fundamental.

Os territórios de visibilização das práticas femininas são resguardados pelos homens, enquanto que nos shows dos homens, as jovens cumprem o papel de intercessoras e auxiliadoras no que for preciso para que o show seja um sucesso. Esse diferencial de posições e funções é evidente quando se trata aqui de uma sobreposição de espacialidades de gênero junto a uma divisão do trabalho religioso que tem a característica de transfigurar as relações sociais em relações legitimamente consagradas. Com efeito, a transparência das práticas femininas e feministas das mulheres do Metanoia contribui para a reprodução de uma determinada visão de mundo religiosa, sem deixar, contudo, de contestar alguns exageros próprios da visão masculinizada que usa a Bíblia como instrumento de reivindicação de qualidades que só uma visão historicista poderia contra-argumentar. E como elas adquiriram o hábito protestante de ler diária ou semanalmente a Bíblia, os contra-argumentos ficam mais densos e raramente sem resposta eficiente por parte daqueles que ainda defendem uma territorialidade essencialmente regida pelo estatuto dos servos masculinos.

\section{Considerações Provisórias}

O Metanoia é, em si mesmo, um signo espacial, um 'geossímbolo' (BONNEMAISON, 2002) que reflete o lado mais extremo do underground cristão. No entanto, o extremo está longe de ser caótico, no sentido de que a cosmologia e as normas de conduta beiram o ascetismo descrito por Max Weber no início do século passado ${ }^{9}$. Um ascetismo que não tem no trabalho a sua realização fundamental, pois se deslocou para a produção da arte 'juvenil', da missão baseada na criatividade e no uso das mídias.

Como um signo, o espaço Metanoia é um recurso para desencadear agenciamentos por parte de seus alvos, ao qual tem a função de exprimir aquilo que jaz oculto (EPSTEIN, 1986, p. 71). Sua função, na atualidade, tem sido promover a coesão identitária e ideológica entre os ministérios e bandas do underground e algumas igrejas evangélicas dispostas a manter o diálogo com esses 'outros cristãos'.

Considerando as apreensões que obtive como observador e ex-frequentador da comunidade, e da cosmovisão defendida pelas mulheres, posso acrescentar que o papel delas no grupo é de suma importância como expressão de 'novos' modos de pensar e viver a fé cristã. Quando uma delas, ao ser indagada sobre a sua função no grupo, sua primeira resposta foi a de que ela tem o papel sagrado de ajudar o marido, e em seguida prosseguiu informando outras tarefas que realiza no grupo. Assim, a percepção que tive é a de que as diferenças entre o Metanoia e as demais instituições protestantes, no que toca à atuação feminina, diferem somente em pontos específicos e estratégicos, pois em um quadro mais geral, as semelhanças são gritantes. É inegável o salto dado em direção ao desligamento do tradicionalismo, embora haja outras tradições que vão se configurando nas novas comunidades cristãs jovens, fato percebido nos novos e pequenos gestos, falas e atitudes que exaltam o pós-moderno e o primitivo, o tecnológico e o artesanal, a ficção e o bíblico...

Desmitificando o paradigma que se tem em senso comum que atribui à mulher cristã a característica submissa, e à mulher underground como 'rebelde', tencionei elucidar a interessante reação observada na junção destas duas características, reunidas em um mesmo grupo: o das mulheres do Ministério Metanoia Podemos afirmar que essas jovens contribuem no impacto gerado entre o meio protestante e underground secular, ao saber da existência do grupo e ter contato com o mesmo: um grupo que se veste, fala e, em alguns pontos, comportam-se, de fato, como outsiders religiosos.

A simbologia dos novos sujeitos femininos cristãos imprime na paisagem urbana uma marca nova, marca essa que se encontra dispersa, atomizadas, mas que, como tudo que acontece no espaço urbano, tem a tendência de florescer e angariar novos protagonistas. São marcas e práticas que refletem o que, no meio secular, já é tido como senso comum: a paridade de gênero. Todavia, a condição de se 'submeter' ao marido ainda prevalece em alguns pontos, mostrando que a masculinidade plural dos cristãos tem um potencial na definição dos espaços religiosos e da interdição dos corpos femininos nos espaços potencialmente perigosos - perigosos tanto no sentido da integridade física quanto da manutenção simbólica da pureza e

Diogo da Silva Cardoso 
delicadeza femininas, mesmo dentro de estilos culturais tão transgressivos e obscuros.

1 No salão inicial, destinado à recepção e sociabilização de todos que ali estão, há ainda o clássico crânio de bode com uma faca transpassada, simbolizando o Diabo (bode) alvejado pela espada de Deus.

2 As frases destacadas em colchetes são rigorosamente a fala usual entre os evangélicos e que se reproduz abruptamente nas comunidades cristãs alternativas.

3 Não à toa, no antigo panfleto do grupo, Enok autodenomina-se como 'missionário urbano'.

4 Disponível

em:

$<$ http://br.noticias.yahoo.com/s/04062009/48/entreteni mento-abrigo.html $>$ Acesso em 2 de dezembro de 2010 .

5 Referência à passagem bíblica na qual Jesus expõe, em forma de parábola, o trigo como os bons homens, e o joio como a estirpe de pecadores da Igreja. O texto na íntegra é: "[...] O reino dos céus é semelhante a um homem que semeou boa semente no seu campo; mas, enquanto os homens dormiam, veio o inimigo dele, semeou joio no meio do trigo, e retirouse. E, quando a erva cresceu e produziu fruto, apareceu também o joio. Então, vindo os servos do dono da casa, lhe disseram: Senhor, não semeaste boa semente no teu campo? Donde vem, pois, o joio? Ele, porém, lhes respondeu: Um inimigo fez isso. Mas os servos lhe perguntaram: Queres que vamos e arranquemos o joio? Não! replicou ele, para que, ao separar o joio, não arranqueis também com ele o trigo. Deixai-os crescer juntos até a colheita, e, no tempo da colheita, direi aos ceifeiros: Ajuntai primeiro o joio, atai-o em feixes para ser queimado; mas trigo, recolhei-o no meu celeiro". (Mateus 13:24-30).

6 Termo evangélico para o músico devidamente consagrado pela Igreja para tocar no 'grupo de louvor'. No Metanoia, o ministério musical chama-se Metanoia WorshipWorship.

7 Rótulos depreciativos dados pelos homens e pelas mulheres 'de boa família' às jovens que 'abordam' e 'seduzem' os motociclistas (maria-gasolina) e os músicos cabeludos de bandas de heavy metal (mariaxampu) somente pelos objetos e pelo status e prestígio que carregam. As marias-palquinho são as garotas que só arranjam compromissos afetivos e amorosos com músicos de bandas de rock e metal - preferencialmente músicos de bandas famosas! Não é preciso dizer que nesse conflito de gêneros e rotulações, há dois problemas: 1) o machismo e a divisão sexual do trabalho e do lazer que persiste nas culturas juvenis; 2) as meninas e mulheres adultas colocam-se como objetos a serem usufruídos pelos homens de prestígio subcultural. Generalizando para toda a juventude brasileira, uma possível transformação dos valores de gênero terá que partir dos dois polos heterossexuais da questão (homens e mulheres).

8 Duas frases ditas por um homem e mulher do Metanoia, respectivamente. Não citarei os nomes para preservá-los.

9 Refiro-me ao seu famoso e polêmico livro 'A ética protestante e o espírito do capitalismo' (2001).

\section{Referências}

BÍBLIA SAGRADA. Bíblia do ministro com concordância: nova versão internacional. São Paulo: Vida, 2007.

BONNEMAISON, Jöel. Viagem em torno do território. In: CORRÊA, Roberto Lobato, ROSENDAHL, Zeny. (Orgs.). Geografia cultural: um século (3). Rio de Janeiro: EDUERJ, 2002. p. 83132.

CANEVACCI, Massimo. Culturas eXtremas. Rio de Janeiro: DP\&A Ed., 2005.

CARDOSO, Diogo da Silva. Guerreando em nome do Senhor: sobre o underground cristão e evangélico no Brasil, suas territorialidades e o exemplo do grupo Metanoia (RJ). Revista Brasileira de História das Religiões. v. 1 n. 3, 2008. [Disponível em: $<$ http://www.dhi.uem.br/gtreligiao/.../guerreando_em nome_do_senhor.pdf $>$ Acesso em 23 de fevereiro de 2009]

CARNEY, George O. Música e lugar. In: CORREAA, Roberto Lobato, ROSENDAHL, Zeny. (Org.). Literatura, música e espaço. Rio de Janeiro: EDUERJ, 2007, p. 123-150.

CLAVAL, Paul. Etnogeografias - conclusão. Espaço

Diogo da Silva Cardoso 
'Mulheres Fortes e com Estilo': Protagonismo musical e territorialidades femininas no movimento underground Cristão

\& Cultura. n. 7, p. 69-74, jan/jun, 1999.

COSTA, Márcia Regina da. Os Carecas de Cristo e as Tribos Urbanas do Underground Evangélico. In: PAIS, José Machado, BLASS, Leila Maria da Silva. (Org.). Tribos Urbanas: Produção Artística e Identidades. São Paulo: Annablume, 2004, p. 43 - 69.

Tribos Urbanas, Comunidade Zadoque e os Carecas de Cristo. In: BERNARDO, Terezinha, TÓRTORA, Silvana. (Org.). Ciências Sociais na atualidade: percursos e desafios. São Paulo: Cortez ed., 2004, p. 241 - 258.

EAGLETON, Terry. A ideia de cultura. São Paulo: EDUNESP, 2003.

EPSTEIN, Isaac. O signo. São Paulo: Ática, 1986.

HAESBAERT, Rogério. Território e multiterritorialidade: um debate. GEOgraphia. v. 9. n. 17, p. 19-45, 2007

KIMBALL, Dan. A igreja emergente: cristianismo clássico para as novas gerações. São Paulo: Editora Vida, 2008.

LOPES, Pedro Alvim Leite. Hell de Janeiro: heavy metal e choques culturais na cidade do Rio de Janeiro. In: DAMASCENO, Francisco José Gomes; MENDONÇA, Amaudson Ximenes. (Org.). Experiências musicais. Fortaleza: Prefeitura Municipal de Fortaleza/EDUECE, 2008, p. 202-216.

Heavy metal no Rio de Janeiro e dessacralização de símbolos religiosos: a música do demônio na cidade de São Sebastião das Terras de Santa Cruz. 2006. Tese (Doutorado em Antropologia Social) - Museu Nacional, Universidade Federal do Rio de Janeiro, Rio de Janeiro.

MARCUS, George E. Ethnography in/of the World System: The Emergence of Multi-Sited Ethnography. Annual Review of Anthropology. v. 24, p. 95-117, 1995.

SILVA, Joseli Maria. Amor, paixão e honra como elementos da produção do espaço cotidiano feminino. Espaço e Cultura, n. 22, p. 97-109, jan./dez. 2007.

Análise do espaço sob a perspectiva do gênero: um desafio para a geografia cultural brasileira. In: ROSENDAHL, Zeny, CORRÊA, Roberto Lobato. (Org.). Geografia: temas sobre espaço e cultura. Rio de Janeiro: EDUERJ, 2005, p. 173-189.

VATTIMO, Gianni, RORTY, Richard, ZABALA, Santiago. $O$ futuro da religião: solidariedade, ironia e caridade. Lisboa: Angelus Novus, 2008.

WEBER, Max. A ética protestante e o espírito do capitalismo. 2. ed. rev. São Paulo: Pioneira Thomson Learning, 2001.

WELLER, Wivian. A presença feminina nas (sub)culturas juvenis: a arte de se tornar visível. Estudos Feministas, v. 13, n. 1, p. 107-126, jan./abr. 2005.
Recebido em 05 de julho de 2010. Aceito em 23 de dezembro de 2011.

Diogo da Silva Cardoso 